\title{
0 esporte como ferramenta política e diplomática: o caso do boicote americano às Olimpíadas de Moscou (1980)
}

\author{
Sport as a political and diplomatic instrument: \\ the American boycott of the Moscow Olympics (1980)
}

\begin{abstract}
Murilo Meihy
Universidade Federal do Rio de Janeiro (UFRJ), Rio de Janeiro / Brasil Doutorado em Língua, literatura e cultura árabe, USP

Email: meihy1@yahoo.com.br

Luana Souza

Universidade Federal do Rio de Janeiro (UFRJ), Rio de Janeiro / Brasil Doutoranda em História, UFRJ
\end{abstract}

\begin{abstract}
Resumo: Neste artigo, buscaremos entender o uso do esporte como ferramenta diplomática e política por países, governos e seus comitês olímpicos, procurando entender o movimento de boicote aos jogos dentro do contexto de disputa política da Guerra Fria e da disputa ideológica entre comunismo e capitalismo. Para isso, é necessário compreender as origens do Esporte Moderno e dos Jogos Olímpicos modernos, em seus contextos e conjunturas iniciais. Analisaremos outro caso de combinação explícita entre esportes e política: o caso das Olimpíadas de Berlim de 1936, realizadas durante o governo nazista de Adolf Hitler. Em seguida, enfocaremos o caso das Olimpíadas de Moscou de 1980, em seu contexto de aumento das tensões entre Estados Unidos e União Soviética e da politização dos jogos através do boicote.
\end{abstract}

Palavras-chave: Esporte; Boicote; Olimpíadas.

\begin{abstract}
This article aims to understand the usage of sport as a diplomatic and political tool by countries, governments and their Olympic committees, seeking to understand the boycott movement inside the political dispute of the Cold War and the ideological dispute between capitalism and communism. For this, it is necessary to understand the origins of the Modern Sport and the modern Olympic Games, in its contexts and initial scenarios. Another event of explicit combination between sports and politics will be examined: the 1936 Berlin Olympics, carried out during the Nazi government of Adolf Hitler. Then, we will analyze the 1980 Moscow Olympics, in its context of increased tensions between the United States and the Soviet Union, and the games politicization through the boycott.
\end{abstract}

KEYwORDS: Sport; Boycott; Olympics. 
FuLiA / UFMG - O esporte como ferramenta política e diplomática

\section{INTRODUÇÃo}

Os Jogos Olímpicos de Moscou, em 1980, foram marcados por um boicote de diversas nações, incluindo os Estados Unidos, que se recusaram ou proibiram a participação de seus atletas nos jogos. 0 uso político do esporte, através da decisão governamental de proibir que seus atletas participassem dos jogos, não foi exclusivo dessa ocasião, sendo possível verificarmos tal atitude em outras edições dos Jogos Olímpicos, apesar da hesitação de instituições como o Comitê Olímpico Internacional (COI) em admitir a politização da competição e seu uso para fins diplomáticos por parte da comunidade internacional. Este artigo tem por objetivo entendermos o uso diplomático e político do esporte no caso do boicote liderado pelos Estados Unidos durante a Olimpíada de Moscou em 1980. Ocorrido durante a Guerra Fria e seu contexto de disputa ideológica, o boicote foi um instrumento diplomático e político para os americanos, com os Jogos Olímpicos sendo utilizados como forma de angariar apoio de outros países. 0 uso dos Jogos Olímpicos como instrumento político e diplomático não foi exclusivo do governo americano em relação às Olimpíadas na União Soviética, com os Jogos Modernos sendo cooptados pelos Estados e nações pelo seu potencial de representação nacional.

\section{O ESPORTE COMO FERRAMENTA DIPLOMÁTICA}

0 esporte moderno teve origem na Inglaterra, a partir da regulamentação e institucionalização de jogos populares. 0 esporte teve inicialmente um caráter educativo, de instrução e disciplina dos corpos. Logo, é apropriado por parte da burguesia como forma de controle de funcionários, como tentativa de evitar envolvimento em atos de violência e faltas no trabalho, e controle dos trabalhadores, com o esporte moderno desenvolvido paralelamente ao processo de industrialização. As escolas estatais e as igrejas também tiveram papel importante no processo de "massificação da prática esportiva". ${ }^{1}$

${ }^{1}$ SIGOLI; ROSE JÚNIOR. A história do uso político do esporte, p. 114. 
FuLiA / UFMG - O esporte como ferramenta política e diplomática

O Olimpismo, movimento desenvolvido por Pierre de Coubertin, um educador, buscava resgatar entre os países um sentimento de representação nacional junto ao universalismo. Com a adesão de valores como fair play, e a regulamentação das atividades competição, com uma base educacional e moral, temos a primeira edição dos Jogos Olímpicos modernos em 1896, em Atenas. Em sua concepção inicial, os jogos seriam organizados por instituições que teriam caráter apolítico e independente, mas a tentativa de distanciar as competições e a política é logo revertida, com os Estados nacionais percebendo o potencial de representação de interesses políticos, ideológicos e econômicos presentes nos jogos. ${ }^{2}$

No pós Primeira Guerra Mundial, em um período de aumento dos nacionalismos, as disputas esportivas passam a serem "campos de vingança" entre nações. ${ }^{3} \mathrm{Na}$ Europa do entre guerras, constata-se a universalização dos jogos, o aumento das entidades e encontros internacionais, e o aumento da cobertura de imprensa. A comunidade esportiva internacional, ao mesmo tempo em que alegava autonomia em relação a governos, se colocava como ator de políticas internacionais. A fácil adaptação do esporte às questões governamentais de determinado país ajuda no processo de politização esportiva: um governo pode dar instruções para seus representantes de entidades esportivas, fazendo com que a independência do movimento esportivo nacional seja prejudicada. Já nos Jogos Olímpicos de 1912, em Estocolmo, são registrados casos de nacionalismos exacerbados e ataques xenofóbicos entre os competidores. ${ }^{4}$

O uso do esporte como símbolo de disputa entre dois sistemas é constante no período da chamada Guerra Fria, com a polarização entre as duas maiores potências do contexto, EUA e a URSS. Em 1921 a URSS já traz o esporte para sua esfera de governo, com a criação do "Esporte Vermelho Internacional", que é afiliado à Internacional comunista. A URSS já deseja integrar os países participantes do COI no

\footnotetext{
${ }^{2}$ SIGOLI; ROSE JÚNIOR. A história do uso político do esporte, p. 115.

${ }^{3}$ ARNAUD. Sport - A Means of National Representation, p. 6.

${ }^{4}$ ARNAUD. Sport - A Means of National Representation, p. 25.
} 
pós Segunda Guerra, e não encontra dificuldade com os líderes do comitê. ${ }^{5}$ A URSS deveria seguir as regulamentações do COI, como a separação do Comitê Olímpico Soviético do governo soviético, o que na prática não existiu: o Comitê sofria grande intervenção estatal, o que não atrapalha a aceitação da URSS no COI em 1951. Outra demonstração do alto grau de intervenção governamental soviética foi a escolha do representante russo no COI. A URSS queria indicar o nome de seu representante para o COI, o que era contra a regulamentação, mas tal intento foi permitido, sendo Kostantin Andrianov escolhido para ocupar o cargo. 0 esporte soviético passou então a ter grande investimento estatal, já que uma ideia de superioridade ideológica era ligada à lógica de qual país levava para casa mais medalhas.

Com o sucesso soviético nos jogos, os EUA e outros países ocidentais começaram a adotar a mesma medida soviética de esportes financiados pelos Estados. ${ }^{6}$ As vitórias e as medalhas podem ser usadas para angariar apoio e demonstrar força, internamente e de forma internacional, de Estados e governos e também como elemento de política internacional. 0 esporte soviético e suas competições seriam também "vitrines" de suas políticas em relação ao resto do mundo: enfrentamento em alguns momentos e détente em outros. Em 1959, o time de basquete soviético perde um título por se recusar a jogar contra o time de Taiwan; em um jogo de eliminatória da Copa do Mundo contra o Chile, ainda sob o governo socialista de Salvador Allende, os soviéticos vencem em Moscou, mas, antes do outro jogo em Santiago, o Chile passa por um golpe militar e passa a ser controlado por Augusto Pinochet: o time da URSS se recusa então a jogar. ${ }^{7}$

0 esporte passa a ser então um dos elementos possíveis de serem trabalhados na diplomacia, segundo Suppo:

\footnotetext{
${ }^{5}$ GUTTMANN. The Cold War and the Olympics, p. 556.

${ }^{6}$ GUTTMANN. The Cold War and the Olympics, p. 557-558.

${ }^{7}$ EDELMAN. Serious Fun, p. 128-129.
} 
Pierre Milza (...) afirma que o esporte possui três dimensões essenciais na política internacional:

1. é componente e reflexo da vida internacional;

2. é revelador do sentimento público; e

3. tem papel relevante em três aspectos precípuos da política estrangeira: . como instrumento de preparação para a guerra, através dos fins guerreiros da educação física e das atividades esportivas (o cidadão soldado) . engendrando imagens de prestígio que podem ser instrumentalizadas pela propagando nacionalista; e

. como meio de aproximação entre países (o mesmo papel que tinham as visitas das esquadras navais no século XIX). ${ }^{8}$

Um dos casos mais conhecidos da "instrumentalização da propaganda nacionalista", comentado por Suppo, foi o caso das Olimpíadas de Berlim, em 1936, realizadas durante o governo nazista e com ameaças de boicote por parte da comunidade internacional. Apesar de a escolha de Berlim como cidade sede ter sido feita em abril de 1931, antes da chegada dos nazistas ao poder, a realização das Olimpíadas em um lugar em que o governo claramente desrespeitava os ideais de Jogos Modernos abertos para todas as raças, credos e cores foi discutida e polemizada por muitos.

\section{AS OLIMPÍADAS DE BERLIM E A AMEAÇA DE BOICOTE}

O uso político do esporte pela Alemanha nazista não foi algo inesperado: em um sistema governamental que abrangia todas as áreas da vida social, artística e econômica, a tentativa de instrumentalização do esporte para fins políticos era apenas mais uma medida de controle de todos os aspectos da vida cotidiana. Berlim foi escolhida para sediar os Jogos Olímpicos em 1931, ainda sob o Governo da República de Weimar. Com Adolf Hitler sendo nomeado chanceler em 30 de janeiro de 1933, ato que representou a chegada do partido nazista ao poder, houve a preocupação inicial com a continuidade dos preparativos para a realização dos Jogos. 0 partido nazista não via com bons olhos o esporte moderno, com seus ideais de igualdade e universalismo. ${ }^{9}$ Joseph Goebbels, ministro da propaganda de Hitler, percebe o

\footnotetext{
${ }^{8}$ SUPPO. Reflexões do lugar do esporte nas relações internacionais, p. 406.

${ }^{9}$ GUTTMANN. The 'Nazi Olympics' and the American Boycott Controversy, p. 31.
} 
FuLiA / UFMG - O esporte como ferramenta política e diplomática

potencial de divulgação da Alemanha nazista presente nas Olimpíadas, e o governo decide apoiar a realização dos jogos de Berlim. As leis raciais de 1935 determinavam, além outras proibições para pessoas de origem judaica, a proibição do uso de campos e equipamentos esportivos públicos por clubes ou atletas judeus. ${ }^{10} \mathrm{~A}$ discussão sobre um possível boicote tem início, e a Alemanha passa a sofrer pressão do Comitê Olímpico Internacional (COI) para garantir a participação de atletas judeus nas competições; o Comitê Olímpico alemão promete seguir o regulamento esportivo internacional. ${ }^{11}$ Avery Brundage, então presidente do Comitê Olímpico Norteamericano, viaja para a Europa em meio a ameaças de boicote de seu país para investigar a situação judaica nos Jogos. Brundage, que tinha a opinião de que esportes e política deveriam ser separados, considerava suficiente a Alemanha seguir as regras esportivas internacionais. No fim, alguns casos de exceção foram aceitos, como o da atleta de origem judaica Helene Mayer, que foi convidada para competir como representante alemã de esgrima nos jogos. 0 caso Meyer foi interpretado como a Alemanha nazista cedendo a pressões internacionais para permitir a participação de atletas judeus nos jogos. ${ }^{12}$

A opinião de Brundage de separação de esporte e política não poderia ser corroborada na Alemanha nazista. 0 processo de "nazificação"13 do esporte, com o governo resgatando ideais de raça ariana e corpos atléticos, e criando associações e grupos de esporte e lazer é parte da ideologia totalitária de controle de todos os aspectos da vida da população, não apenas através do terror, mas também por meio de mobilização e adesão. ${ }^{14}$ Os atletas participantes escolhidos para competir pela Alemanha juraram obedecer às regulamentações impostas pelo regime nazista e representar a nação alemã. ${ }^{15}$ Enquanto isso, Brundage designava as tentativas de mobilização por boicotes aos Jogos Olímpicos de Berlim como ameaças de judeus e

\footnotetext{
${ }^{10}$ KRÜGER. "Once the Olympics are through, we'll beat up the Jew", p. 355.

${ }^{11}$ GUTTMAN. The 'Nazi Olympics' and the American Boycott Controversy, p. 34.

12 KRÜGER. "Once the Olympics are through, we'll beat up the Jew", p. 360.

${ }^{13}$ BACHRACH. The Nazification of German Sport, p. 28.

${ }^{14}$ CORNELSEN. Totalitarismo, p. 128.

${ }^{15}$ BACHRACH. The Nazification of German Sport, p. 34.
} 
FuLiA / UFMG - O esporte como ferramenta política e diplomática

comunistas. ${ }^{16}$ Kruger argumenta que a principal preocupação de Brundage não era com a situação judaica durante os jogos, mas com a realização das Olimpíadas sem maiores interferências e de maneira pacífica. ${ }^{17}$

Por fim, os Estados Unidos enviam seus atletas para Berlim e encontram a cidade preparada para receber as delegações internacionais, com a retirada estratégica de placas e avisos de conotação racial, e com notícias e reportagens de cunho positivo para a Alemanha: o Ministério de Propaganda emite uma ordem para que os aspectos raciais dos competidores não sejam comentados na cobertura dos jogos. ${ }^{18}$ Antes dos jogos, o governo nazista faz uma "limpeza" nas ruas de Berlim e envia cerca de 800 ciganos para campos de concentração ainda em construção. ${ }^{19}$

Apesar das tentativas (especialmente por parte de Brundage) de separar a questão do contexto do governo nazista e da situação racial na Alemanha dos esportes, a própria organização esportiva era parte essencial do plano governamental durante o Terceiro Reich. A hesitação inicial do governo nazista em admitir Berlim como sede dos Jogos dá lugar à sua instrumentalização, como forma de controle dos cidadãos e, no âmbito internacional, como um instrumento diplomático que elevaria Berlim a "vitrine" da Alemanha nazista. A recusa por parte de instituições esportivas em apoiar um possível boicote, ou mesmo averiguar mais a fundo a situação dos atletas judeus nos Jogos, é ressonante: as organizações esportivas tendem a ter políticas mais conservadoras do que a sociedade em geral. ${ }^{20}$ Pierre de Coubertin visita Berlim em 1935 e, em demonstração de apoio contra o movimento de boicote, declara sua confiança no andamento e no sucesso dos Jogos de 1936:21 o esporte e a política se unem como forma de garantir a realização dos Jogos Olímpicos sob o regime nazista.

\footnotetext{
${ }^{16}$ GUTTMANN, Allen. The 'Nazi Olympics' and the American Boycott Controversy, p. 39.

${ }^{17}$ KRUGER. "Once the Olympics are through, we'll beat up the Jew".

${ }^{18}$ GUTTMANN. The 'Nazi Olympics' and the American Boycott Controversy, p. 45.

${ }^{19}$ BACHRACH. The Nazi Olympics, p. 85.

${ }^{20}$ KRÜGER. "Once the Olympics are through, we'll beat up the Jew", p. 370.

${ }^{21}$ GUTTMANN. The 'Nazi Olympics' and the American Boycott Controversy, p. 37.
} 
FuLiA / UFMG - O esporte como ferramenta política e diplomática

\section{OLIMPÍADAS DE MOSCOU: ACIRRAMENTO DAS TENSÕES E BOICOTE}

Jimmy Carter chega à presidência dos EUA em 1977 com um discurso de outsider: um candidato que seria diferente dos já presentes na política. Prometeu encerrar o programa de armas nucleares ${ }^{22}$ e, durante a campanha de eleição, não apresentou um programa de política externa definido. Seu secretário de Estado, Cy Vance, e seu conselheiro de segurança nacional, Zbigniew Brzezinski, discordavam de pontos chaves em relação à política externa da Guerra Fria: Vance queria trabalhar e cooperar com os soviéticos, com um plano de desarmamento mútuo, independente de supostas influências soviéticas em outros países, enquanto Brzezinski acreditava que qualquer ato de suposta agressão soviética deveria ser interpretado como ameaça. A diplomacia do governo Carter deteriorou-se diante dessas duas visões conflituosas, e a partir de seu governo podemos observar um aumento nas tensões entre EUA e URSS, um momento chamado de "A Nova Guerra Fria". Enfrentando uma crise no Irã ${ }^{23}$ e com o governo apresentando-se como inerme internacionalmente, Carter vai para a disputa pela reeleição com alto índice de rejeição, com $82 \%$ dos americanos considerando sua política externa ruim. ${ }^{24} \mathrm{Em} \mathrm{1979,} \mathrm{o} \mathrm{governo} \mathrm{Carter} \mathrm{começa} \mathrm{a} \mathrm{aumentar} \mathrm{o} \mathrm{investimento}$ americano em tecnologia militar, com um aumento no orçamento de defesa que continuaria até o governo de Ronald Reagan. As tensões na fronteira entre a URSS e o Afeganistão culminam com uma guerra, com os soviéticos invadindo o território afegão em dezembro de 1979 e encontrando resistência, principalmente por parte de guerrilhas muçulmanas. Diante do ocorrido, o governo americano impõe sanções contra a URSS e pede outro aumento do orçamento militar. ${ }^{25}$ Sanções para exportação de tecnologia e trigo para a URSS são impostas, e um boicote às Olimpíadas de Moscou

\footnotetext{
${ }^{22}$ GADDIS. The Cold War, p. 201.

${ }^{23}$ O Irã, até 1979, foi controlado por xá Reza Pahlavi, aliado ocidental com um grande número de armas importadas dos Estados Unidos entre 1974 e 1978. Enfrentando oposição, grandes manifestações e greves, o xá é deposto por uma revolução e vai para os EUA para tratamento médico. No Irã, o poder passa a ser controlado pelo aiatolá Ruhollah Khomeini, ferrenho opositor dos EUA, e a embaixada americana é invadida por um grupo de pessoas que fazem 69 funcionários reféns por 444 dias.

${ }^{24}$ LAFEBER. America, Russia, and the Cold War, 1945-2002, p. 315.

${ }^{25}$ GADDIS. The Cold War, p. 211.
} 
FuLiA / UFMG - O esporte como ferramenta política e diplomática

de 1980 foi determinado pelos EUA, com 67 países aderindo ao boicote e outras nações deixando para os atletas a escolha de competir ou não. Os atletas americanos foram proibidos de participar, com o governo Carter ameaçando cancelar o passaporte dos competidores americanos que participassem das Olimpíadas.

O movimento pelo boicote às Olimpíadas de Moscou teve início por questões além da participação soviética na Guerra do Afeganistão. A China, se candidatando para participar do Movimento Internacional Olímpico em 1975, enfrenta dificuldades com a questão de Taiwan. ${ }^{26}$ com o Comitê Olímpico oferecendo a participação de "duas Chinas": duas delegações representando a China, uma sob a bandeira de “República da China (Taipei)” e outra sob “República da China (Pequim)”. Taiwan se recusou e o Comitê aceitou apenas uma China competindo nas Olimpíadas de inverno. Posteriormente, a China adere ao boicote, se alinhando assim ao seu mais recémaliado, os EUA. Israel também deseja participar dos Jogos, apesar de não manter relações diplomáticas com Moscou, e a URSS não poderia banir os israelenses por conta dos regulamentos do COI. As relações entre os dois países sempre foram tensas, por conta da perseguição do governo soviético aos judeus na Rússia, e as críticas ao sionismo. Israel decide não participar dos Jogos Olímpicos de 1980 por apoio aos EUA.27

A ideia do boicote surgiu primeiramente com a situação de Anatoly Shransky, um ativista de direitos humanos soviético de origem judaica, que foi acusado de traição e levado a julgamento em uma tentativa vista pela comunidade internacional de silenciar dissidentes. ${ }^{28}$ Os EUA, acusados no pós-Vietnã de interferência em países do Terceiro Mundo, desenham uma estratégia de iniciativa de direitos humanos, em que países que fizessem acordos financeiros com os americanos deveriam seguir uma série de medidas para assegurar o cumprimento de critérios estabelecidos pelos EUA. Brzezinski acreditava que isso faria com que os EUA e o governo Carter ganhassem maior respeitabilidade com os países do Terceiro Mundo e que ajudar a garantir o

\footnotetext{
${ }^{26}$ Após a Guerra Civil Chinesa e a conquista do poder pelo Partido Comunista Chinês, o governo da República da China foge para a ilha de Taiwan, onde continua a se declarar como representante legítimo do governo chinês.

${ }^{27}$ KANIN. The Olympic Boycott in the Diplomatic Context, p. 4.

${ }^{28}$ KANIN. The Olympic Boycott in the Diplomatic Context, p. 5.
} 
FuLiA / UFMG - O esporte como ferramenta política e diplomática

respeito à democracia refletiria a essência americana. 0 boicote acaba sendo então uma forma de colocar em prática a política americana de direitos humanos. Carter oferece então uma solução para os Estados Unidos competirem nos Jogos Olímpicos de 1980: caso a URSS não retirasse em um mês as tropas do Afeganistão, as competições deveriam ser transferidas para outro país. 0 prazo de um mês ou a possibilidade de transferência do local dos jogos parecia impossível para os especialistas: era pouco tempo para angariar suporte de outros países, e o prazo acabava com a possibilidade de negociação com a URSS. ${ }^{29}$

O Comitê Olímpico Americano, por sua vez, critica a politização do esporte no caso do boicote, e tenta dissuadir o governo e a opinião pública americana do boicote. As pesquisas de opinião demonstravam, porém, o apoio de grande parte da população americana ao boicote. ${ }^{30} \mathrm{~A}$ demora, tanto pelo governo americano quanto pelo Comitê, em confirmar o boicote oficial (o governo anuncia em fevereiro de 1980, e o Comitê o confirma em abril do mesmo ano), fez com que os EUA demorassem em angariar apoio de outros países. Os comitês olímpicos enfrentam dificuldade dos comitês para chegarem a uma decisão consensual: foi votada, pelos comitês da Europa ocidental, a determinação de permitir que seus atletas participassem sem bandeira, uniformes ou se recusando a participar da cerimônia de abertura, caso assim o desejassem. Oficiais olímpicos acreditavam que isso garantiria a separação entre esporte e política. ${ }^{31}$

Os resultados do boicote não foram ideais para os EUA: apesar de conseguirem que grandes países aderissem ao boicote, a recusa de alguns países de aderirem a tal intento irritou o governo americano. 67 países não participaram dos jogos, com a estimativa de 45 a 50 nações tendo sua ausência justificada pela adesão ao boicote. ${ }^{32}$ A hesitação e a demora de alguns países e de seus respectivos comitês olímpicos em aderirem ao boicote demonstraram que não haveria uma resposta unificada sobre a situação no Afeganistão. Para a URSS, a ausência dos países, com 80 nações presentes,

\footnotetext{
${ }^{29}$ SARANTAKES. Jimmy Carter's Disastrous Olympic Boycott, p. 2.

${ }^{30}$ KANIN. The Olympic Boycott in the Diplomatic Context, p. 6.

${ }^{31}$ KANIN. The Olympic Boycott in the Diplomatic Context, p. 15.

${ }^{32}$ COMITÉ OLÍMPICO INTERNACIONAL. Moscow 1980.
} 
FuLiA / UFMG - O esporte como ferramenta política e diplomática

fez com que o número de participantes fosse o menor desde 1956. Nos Jogos Olímpicos seguintes, na cidade norte-americana de Los Angeles em 1984, a URSS se recusou a participar, alegando falta de segurança para a equipe soviética e propaganda anticomunista nos veículos de comunicação americanos. ${ }^{33}$

\section{CONSIDERAÇõES FINAIS}

O boicote foi o uso diplomático do esporte. Utilizando a competição como forma de angariar apoio em um contexto de enfraquecimento americano e de seu governo, Jimmy Carter empregou a diplomacia como forma de fortalecer seu país. Os resultados não foram os ideais nem para os EUA nem para a URSS, mas o boicote foi a consequência do grau cada vez maior de politização esportiva do contexto da Guerra Fria. Não foi a primeira ocasião nem seria a última em que observamos esse fenômeno: a Alemanha nazista sob a égide de Hitler e as Olimpíadas de Munique, em 1972, em que 11 competidores israelenses foram mortos por um grupo palestino, são exemplos. Outro caso de boicote a um país, dessa vez apoiado pelo COI, foi o caso da África do Sul durante o regime do apartheid, que foi banida das competições entre 1964 e 1991,34 com base na sua discriminação de raças que entraria em conflito com a resolução da entidade esportiva de igualdade entre raças, credos e cores, em um movimento liderado primeiramente pela URSS, e depois por países africanos recém-descolonizados.

O uso político do esporte parece inevitável a partir do momento em que se mobilizam sentimentos de nacionalismo, ou até mesmo de internacionalismo. Kanin comenta: "O esporte político serve para nos lembrar que relações internacionais, não importa quão secreta sejam conduzidas, são compelidas às massas que, na análise final, servem como audiência e juiz daqueles que as conduzem". ${ }^{35}$ A ideia inicial dos Jogos Modernos de suposta neutralidade e amadorismo dá lugar para uma lógica de

\footnotetext{
${ }^{33}$ GUTTMANN. The Cold War and the Olympics, p. 564.

${ }^{34}$ COMITÉ OLÍMPICO INTERNACIONAL. South Africa.

${ }^{35}$ KANIN. The Olympic Boycott in the Diplomatic Context, p. 24. No original temos: "Political Sport serves to remind us that international relations, no matter how secretly conducted, are bound to the mass publics who, in the final analysis, serve as both audience and judge of those who lead them".
} 
mercado e política, com o aumento de público e participantes. Suppo comenta a "geopolitização do esporte", em que não apenas disputas e rivalidades ditariam a lógica dos jogos, mas também a cooperação internacional entre países. ${ }^{36} \mathrm{Em}$ um momento de aumento das tensões entre os EUA e a URSS e disputas ideológicas de dois sistemas, o uso dos Jogos Olímpicos como moeda diplomática e forma de demonstrar apoio - ou não - aos EUA, se encaixa na lógica geopolítica do contexto. A partir do momento em que o esporte é reivindicado pelos governos, seja pela forma de financiamentos, incentivo aos nacionalismos ou como instrumento diplomático, ele não pode ser apolítico.

\section{REFERÊNCIAS}

ARNAUD, Pierre. Sport - A Means of National Representation. In: ARNAUD, Pierre; RIORDAN, Jim. Sport and International Politics - The Impact of Fascism and Communism on Sport. Nova York: Routledge, 1998, p. 3-13.

ARNAUD, Pierre; RIORDAN, Jim. Sport and International Politics: The Impact of Fascism and Communism on Sport. Nova York: Routledge, 1998.

BACHRACH, Susan. The Nazi Olympics. In: BACHRACH, Susan. The Nazi Olympics: Berlin 1936. Boston; Nova York; London: Brown and Company, 2000, p. 73-105.

BACHRACH, Susan D. The Nazification of German Sport. In: BACHRACH, Susan. The Nazi Olympics: Berlin 1936. Boston; Nova York; London: Brown and Company, 2000, p. 27-41.

COMITÊ OLÍMPICO INTERNACIONAL. Moscow 1980. Disponível em: https://www.olympic.org/moscow-1980. Acesso em: 01/11/17.

COMITÊ OLÍMPICO INTERNACIONAL. South Africa. Disponível em: https://www.olympic.org/south-africa. Acesso em 19 nov. 2017.

CORNELSEN, Elcio. Totalitarismo. Literatura e Autoritarismo, n. 14 - jul.-dez. 2009, p. 125-139. Disponível em: https://bit.ly/2rj49DR. Acesso em: 15 nov. 2017.

EDELMAN, Robert. Serious Fun - A History of Spectator Sports in the USRR. Nova York: Oxford University Press, 1993.

GADDIS, John L. The Cold War. Nova York: The Penguin Press, 2005.

${ }^{36}$ SUPPO. Reflexões do lugar do esporte nas relações internacionais, p. 420. 
GUTTMANN, Allen. The Cold War and the Olympics. International Journal. v. 43, n. 4, Sport in World Politics. Fall, 1988, p. 554-568. Disponível em: https://bit.ly/2lc80Mn. Acesso em: 05 nov. 2017.

GUTTMANN, Allen. The 'Nazi Olympics' and the American Boycott Controversy. In: ARNAUD, Pierre; RIORDAN, Jim. Sport and international politics: The Impact of Fascism and Communism on Sport. Nova York: Routledge, 1998, p. 31-51.

KANIN, David B. The Olympic Boycott in the Diplomatic Context. Journal of Sport and Social Issues. v. 4, issue 1, 1 mar. 1980, p. 1-24. Disponível em: https://bit.ly/2KB8Xwo. Acesso em: 05 nov. 2017.

KRÜGER, Arnd. "Once the Olympics are through, we'll beat up the Jew" German Jewish Sport 1898-1938 and the Anti-Semitic Discourse. Journal of Sport History. v. 26, n. 2, p. 353-375, Summer 1999. Disponível em: https://bit.ly/2w8paGb. Acesso em: 19 nov. 2017.

LAFEBER, Walter. America, Russia, and the Cold War, 1945-2002. 9. ed. New York: McGraw-Hill, 2003.

SARANTAKES, Nicholas E. Jimmy Carter's Disastrous Olympic Boycott. Politico Magazine. 9 fev. 2014. Disponível em: https://politi.co/2kx2Lgc. Acesso em: 19 nov. 2017.

SIGOLI, Mário André; ROSE JÚNIOR, Dante De. A história do uso político do esporte. Revista Brasileira de Ciência e Movimento. Brasília, v. 12, n. 2, p. 111119, jun. 2004. Disponível em: https://bit.ly/2npVxeG. Acesso em: 15 nov. 2017.

SUPPO, Hugo. Reflexões do lugar do esporte nas relações internacionais. Contexto Internacional. Rio de Janeiro, v. 34, n. 2, jul./dez. 2012, p. 397-433. Disponível em: https://bit.ly/2HRoeY3. Acesso em: 19 nov. 2017. 